\title{
PERBAIKAN WORKSTATION DI PT. YUSHIRO INDONESIA UNTUK MENGURANGI RESIKO KELUHAN MUSKULOSKELETAL
}

\author{
Dene Herwanto ${ }^{1}$, Acep Purnama ${ }^{2}$, Adi Prianto ${ }^{3},{\text { Kristian } \mathrm{Adi}^{4}}^{4}$ \\ ${ }^{1}$ Program Studi Teknik Industri, Universitas Singaperbangsa Karawang \\ ${ }^{2,3,4}$ Mahasiswa Program Studi Teknik Industri, Universitas Singaperbangsa Karawang \\ "Email: deneherwanto@yahoo.com
}

\begin{abstract}
ABSTRAK
Salah satu pekerjaan yang masih dilakukan secara manual di PT. Yushiro Indonesia adalah penuangan bahan baku berupa cairan kimia pada saat proses pencampuran bahan. Pada saat penuangan cairan kimia tersebut, operator banyak melakukan aktivitas manual material handling yang tidak tepat dan tidak alami, sehingga timbul beberapa keluhan muskuloskeletal, seperti sakit pinggang, sakit punggung, sakit leher, dan sebagainya. Hasil penelitian menunjukkan bahwa nilai RWL dan LI yang terjadi dalam proses penuangan cairan kimia selama ini secara berturut-turut adalah 9,7 dan 1,7 yang berarti bahwa pekerjaa yang dilakukan mengandung resiko terjadinya keluhan. Untuk mengatasi hal itu, selanjutnya dilakukan modifikasi pada alat bantu, yang sebelumnya menggunakan trolley diganti dengan table lifter yang dapat disetel ketinggiannya. Selain itu juga dengan mengubah jarak beban ke pusat tubuh. Hasil modifikasi menunjukkan nilai RWL dan LI berturut-turut sebesar 13,1 dan 0,96. Dengan demikian, modifikasi ini berhasil menurunkan resiko terjadinya muskuloskeletal.
\end{abstract}

Kata kunci: manual material handling, recommended weight limit, lifting index

\begin{abstract}
One of the works that are still done manually in the PT. Yushiro Indonesia is pouring a liquid chemical raw materials during the process of mixing the ingredients. At the time of pouring the liquid chemicals, many operators do manual material handling activities are improper and unnatural, causing some musculoskeletal complaints, such as back pain, back pain, neck pain, and so on.

The results showed that the RWL and LI values that occur in the process of pouring liquid chemicals during this time in a row was 9.7 and 1.7, which means that pekerjaa that do contain the risk of complaints. To overcome this, the subsequent modification of tools, which previously used the trolley to be replaced with a table lifter adjustable height. In addition, by changing the distance of the load to the center of the body. The results show the value modification RWL and LI respectively by 13.1 and 0.96. Thus, this modification successfully reduce the risk of musculoskeletal
\end{abstract}

Keywords: manual material handling, recommended weight limit, lifting index 


\section{PENDAHULUAN}

Meskipun perkembangan teknologi terkini memungkinkan perusahaan untuk mengadopsi mesin-mesin yang bersifat otomatis dalam proses produksinya, ada pekerjaan-pekerjaan tertentu yang tidak bisa dilakukan dengan mesin, melainkan harus menggunakan tenaga manusia. Salah satunya adalah pekerjaan penuangan cairan kimia ke dalam tangki mixer pada proses pencampuran di bagian produksi sebagaimana yang berlangsung di PT. Yushiro Indonesia, Karawang.

PT. Yushiro Indonesia merupakan perusahaan yang bergerak di bidang oli pelumas dan cairan kimia. Pengamatan awal menunjukkan bahwa pada saat penuangan cairan kimia tersebut, karyawan banyak melakukan aktivitas manual material handling yang tidak tepat dan tidak alami. Akibatnya, timbul beberapa keluhan muskuloskeletal yang dialami oleh karyawan, seperti sakit pinggang, sakit punggung, sakit leher, dan sebagainya.

Grandjean (1993) menjelaskan bahwa keluhan muskoloskeletal adalah keluhan pada bagian-bagian otot skeletal yang dirasakan oleh seseorang mulai dari keluhan yang sangat ringan sampai sangat sakit. Apabila otot menerima beban statis secara berulang dalam jangka waktu yang lama akan dapat menyebabkan keluhan berupa kerusakan pada sendi, ligament dan tendon. Keluhan inilah yang biasanya disebut sebagai musculoskeletal disorder (MSDs) atau cedera pada sistem muskuloskeletal.

Penelitian ini bertujuan untuk memperbaiki sikap kerja karyawan saat melakukan pekerjaan penuangan sehingga dapat mengurangi keluhan muskuloskeletal yang dialami oleh karyawan. Dengan demikian, karyawan akan dapat bekerja dengan lebih aman dan nyaman, dan pada akhirnya dapat meningkat produktivitasnya.

\section{METODOLOGI PENELITIAN}

Penelitian ini dimaksudkan untuk mengurangi terjadinya keluhan musculoskeletal yang dialami oleh karyawan. Penelitian diawali dengan cara melihat secara langsung cara dan sikap kerja karyawan saat melakukan proses penuangan cairan kimia, khususnya pada bagian mixing line mesin Mixing Tank nomor C - 104. Teknik wawancara digunakan untuk mengetahui keluhan yang dialami oleh karyawan saat melakukan proses penuangan cairan kimia.

Berdasarkan hasil dokumentasi yang diperoleh saat mengamati proses kerja karyawan, selanjutnya dilakukan perhitungan RWL (recommended weight limit) dan LI (lifting index) agar dapat dilakukan evaluasi untuk mengetahui apakah pekerjaan tersebut aman atau tidak. Apabila hasil evaluasi menunjukkan bahwa pekerjaan tidak aman, maka akan dicari solusi berupa modifikasi pekerjaan untuk mengatasi ketidakamanan tersebut.

Langkah selanjutnya adalah melakukan pengukuran RWL dan LI dari pekerjaan yang sudah dimodifikasi. Apabila hasil pengukuran menunjukkan pekerjaan aman, maka solusi tersebut akan dijadikan standar terhadap pekerjaan yang bersangkutan. Tetapi apabila hasil pengukuran menunjukkan bahwa pekerjaan masih belum aman, maka perlu dicarikan solusi yang lain hingga pekerjaan menjadi dalam kondisi aman.

\section{HASIL DAN PEMBAHASAN}

Hasil wawancara terhadap 6 (enam) orang operator produksi pada bagian mixing line mesin Mixing Tank nomor C - 104 saat gerakan mengambil dan mengangkat bahan baku ke mixing tank dengan beban $12,6 \mathrm{~kg}$ menunjukkan bahwa operator mengalami beberapa keluhan muskuloskeletal sebagaimana terlihat pada Tabel 1 dan gambar 1 berikut ini.

Tabel 1. Keluhan yang Dialami Operator

\begin{tabular}{lcc}
\hline \multicolumn{1}{c}{ Jenis Keluhan } & Jumlah & Persentase \\
\hline Sakit Pinggang & 4 & 66,7 \\
Sakit Bahu & 5 & 83,3 \\
Sakit Leher & 4 & 66,7 \\
Sakit Punggung & 6 & 100 \\
Sakit Lengan & 2 & 33,3 \\
\hline
\end{tabular}

Sumber: Hasil wawancara, 2015

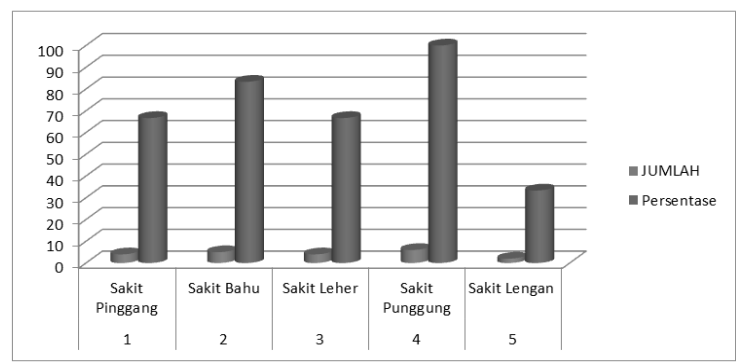

Gambar 1. Grafik Jenis Keluhan yang dialami Operator (Sumber: Hasil wawancara, 2015)

Proses kerja yang dilakukan oleh operator selama pekerjaan penuangan cairan kimia ke dalam tangki mixer ditunjukkan dalam gambar 2 dan 3 di bawah ini.

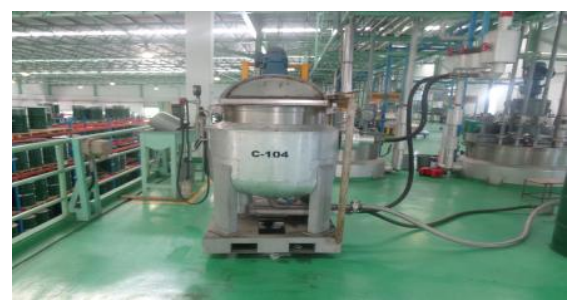

Gambar 2. Mixing Tank C-104 (Sumber: PT. Yushiro Indonesia, 2015) 
Dene Herwanto et.al : Perbaikan Workstation di PT. Yushiro Indonesia untuk Mengurangi Resiko Keluhan Muskuloskeletal Jurnal Teknologi 8 (2) pp 71- 76 (C) 2016

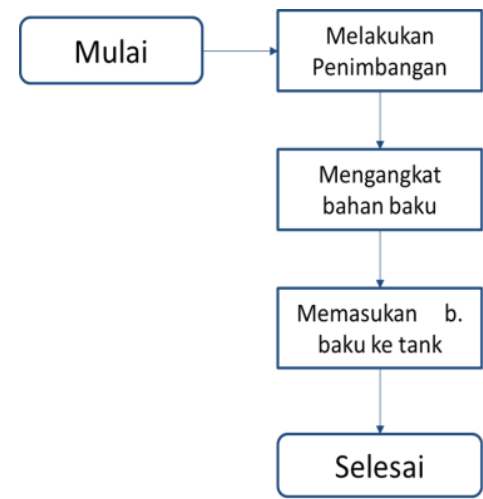

Gambar 3. Diagram Alir Proses Penuangan Cairan ke dalam Tangki Mixer

(Sumber: PT. Yushiro Indonesia, 2015)

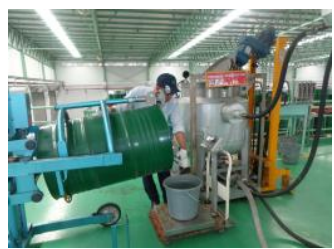

(a)

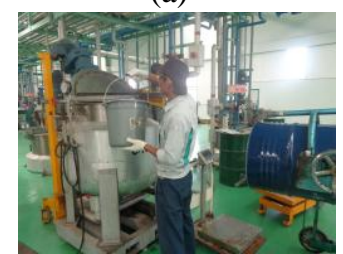

(c)

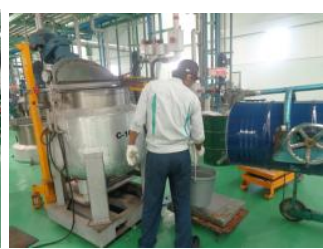

(b)

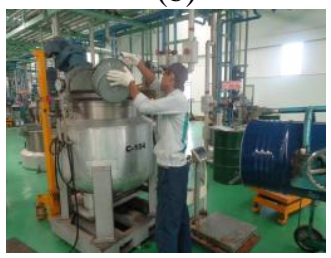

(d) (a) penimbangan bahan baku

(b) pengangkatan bahan baku

(c) persiapan penuangan

(d) penuangan bahan baku

Gambar 4. Proses Kerja Penuangan Cairan Kimia ke dalam Tangki Mixer

(Sumber: PT. Yushiro Indonesia, 2015)

\section{ANALISIS DAN PEMBAHASAN}

\section{Perhitungan RWL dan LI}

Gambar 5 di bawah ini adalah sketsa dari pekerjaan pekerjaan penuangan cairan kimia ke dalam tangki mixer.

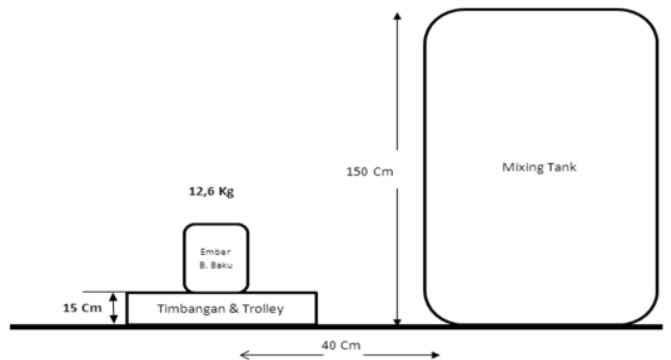

Gambar 5. Sketsa Proses Penuangan Cairan Kimia ke dalam Tangki Mixer

(Sumber: Hasil Pengumpulan Data, 2015)
Berdasarkan data yang didapat dari pengangkatan beban pada proses mixer di bagian produksi, ketika operator mengambil bahan baku dengan berat $12,6 \mathrm{~kg}$ di atas timbangan dan trolley $15 \mathrm{~cm}$ dan mengangkat ke sebuah Mixing tank dengan ketinggian $150 \mathrm{~cm}$ dari lantai. Jarak beban terhadap titik pusat tubuh $40 \mathrm{~cm}$. Sudut simetri putaran yang dibentuk tubuh $45^{\circ}$ dan operator melakukan pengangkatan sebanyak 1 kali / 4 menit (0.25 Lift/menit), maka perhitungan beban kerja sebagai berikut:

\section{RWL $=$ LC $\times$ HM $\times$ VM $\times$ DM $\times$ AM $\times$ FM $\times C M$}

Keterangan :

RWL = Recommended Weight Limit

$\mathrm{HM}=$ Faktor pengali horizontal

$\mathrm{VM}=$ Faktor pengali vertikal

$\mathrm{DM}=$ Faktor pengali perpindahan

$\mathrm{FM}=$ Faktor pengali frekuensi

$\mathrm{AM} \quad=$ Faktor pengali asimetrik

$\mathrm{CM} \quad=$ Faktor pengali kopling

LC = Konstanta pembebanan

Penyelesaian:

$L=12.6 \mathrm{Kg}$

$L C=23 \mathrm{Kg}$

$V=15 \mathrm{Cm}$

Handle Fair $=0,95$

$D=135 \mathrm{Cm}$

$\mathrm{H}=40 \mathrm{Cm}$

$A=45^{\circ}$

\section{Perhitungan:}

$H M=25 / H=25 / 40=0.63$

$V M=1-0,00326|V-75|=1-0,00326|15-75|=0,8$

$D M=0,82+4,5 / D=0.82+4.5 / 135=0.85$

$F M=1$ Lift/4menit $(0,25 \mathrm{Lift} /$ menit $)$

$A M=1-0.0032 \times A=1-0.0032 \times 45=0.86$

$C M=0,95$

$L C=23 \mathrm{~kg}$

Sehingga :

$$
\begin{aligned}
R W L & =L C \times H M \times V M \times D M \times A M \times F M \times C M \\
& =23 \times 0.63 \times 0.8 \times 0.85 \times 0.86 \times 0.92 \times 0.95 \\
& =7,4
\end{aligned}
$$

Maka Lifting Index:

$L i=\frac{\text { Load }}{\text { RWL }}=\frac{126}{7.4}=1,7$

Dari hasil penghitungan diatas dapat disimpulkan mengangkat bahan baku dengan LI > 1,0 mengindikasikan adanya risiko mengangkat yang berhubungan dengan nyeri yang dikeluhkan para operator.

Karena LI>1,0 maka dilakukan modifikasi untuk mendapatkan nilai LI sama dengan atau kurang dari 1,0. Modifikasi dilakukan dengan mengubah desain HM, VM, DM, AM, FM, dan CM. 
Dalam penelitian ini, modifikasi dilakukan pada area HM dan VM, yaitu dengan cara memodifikasi peralatan yang dipakai dalam proses penimbangan. Biasanya, dalam proses penimbangan, timbangan yang digunakan diletakkan di atas trolley. Untuk memperbaiki kondisi yang ada, selanjutnya dilakukan penggantian trolley dengan peralatan lain berupa semacam meja yang dapat disetel ketinggiannya (Table Lifter), dimana secara umum Table Lifter ini disetting ketinggiannya setinggi 80 $\mathrm{cm}$. Selain itu, jarak beban terhadap titik pusat tubuh juga dimodifikasi dari $45 \mathrm{~cm}$ menjadi $30 \mathrm{~cm}$.

Table Lifter yang digunakan dapat dilihat pada gambar 6, sedangkan hasil modifikasi ditunjukkan pada gambar 6 dan 7 di bawah ini.

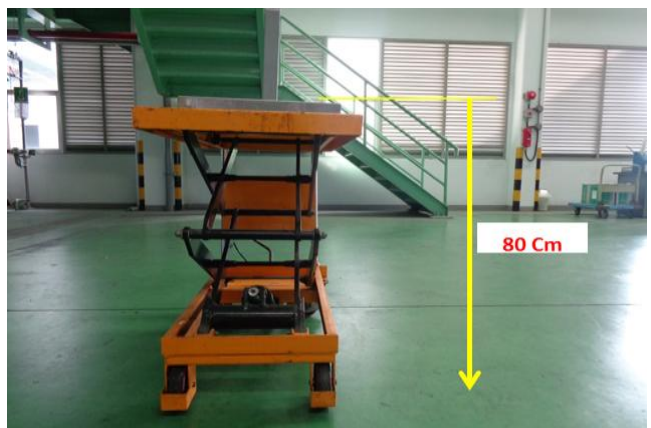

Gambar 6. Gambar Table Lifter Beserta Timbangan (Sumber: PT. Yushiro Indonesia, 2015)

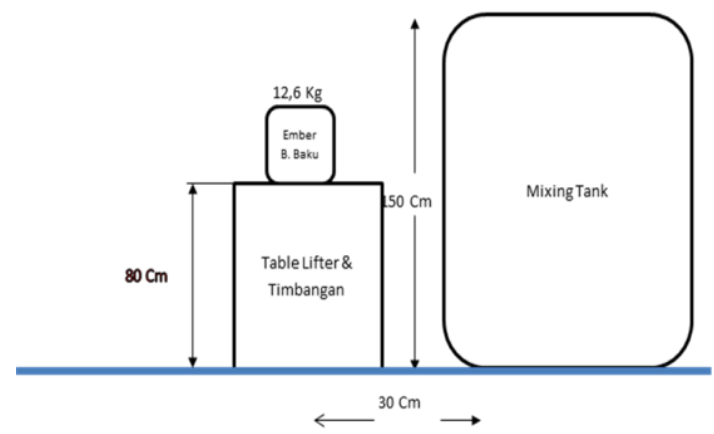

Gambar 7. Dimensi Jarak Tanki Dengan Bahan Baku Modifikasi

(Sumber: Hasil Pengolahan Data, 2015)

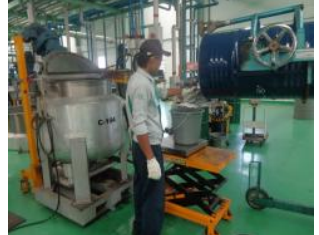

(a)

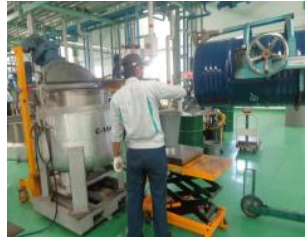

(b) (a) penimbangan bahan baku

(b) pengangkatan bahan baku

(c) penuangan bahan baku

Gambar 8. Proses Kerja Penuangan Bahan ke dalam Tangki Mixer (setelah modifikasi) (Sumber: Hasil Pengolahan Data, 2015)

Sebelum Modifikasi :

$$
\begin{aligned}
& L=12.6 \mathrm{Kg} \\
& L C=23 \mathrm{Kg} \\
& V=15 \mathrm{Cm} \\
& \text { Handle Fair }=0,95 \\
& D=135 \mathrm{Cm} \\
& H=40 \mathrm{Cm} \\
& A=45^{\circ}
\end{aligned}
$$

Setelah Modifikasi :

$L=12.6 \mathrm{Kg}$

$L C=23 \mathrm{Kg}$

$V=80 \mathrm{Cm}$

Handle Fair $=0,95$

$\mathrm{D}=70 \mathrm{Cm}$

$\mathrm{H}=30 \mathrm{Cm}$

$A=45^{\circ}$

Dari hasil modifikasi area HM dan VM perhitungannya sebagai berikut :

Penyelesaian:

$L=12.6 \mathrm{Kg}$

$L C=23 \mathrm{Kg}$

$V=80 \mathrm{Cm}$

Handle Fair $=0,95$

$\mathrm{D}=70 \mathrm{Cm}$

$H=30 \mathrm{Cm}$

$A=45^{\circ}$

\section{Perhitungan:}

$H M=25 / H=25 / 30=0.83$

$V M=1-0,00326|V-75|=1-0,00326|80-75|=0,99$

$D M=0,82+4,5 / D=0.82+4.5 / 70=0.88$

$F M=1$ Lift/4menit $(0,25$ Lift/menit $)$

$A M=1-0.0032 \times A=1-0.0032 \times 45=0.86$

$C M=0,95$

$L C=23 \mathrm{~kg}$ 
Sehingga :

$R W L=L C \times H M \times V M \times D M \times A M \times F M \times C M$ $=23 \times 0.83 \times 0.99 \times 0.88 \times 0.86 \times 0.97 \times 0.95$ $=13.1$

Maka Lifting Index:

$L i=\frac{\text { Load }}{R W L}=\frac{12.6}{13.1}=0.96$

Dari hasil penghitungan diatas dapat disimpulkan mengangkat bahan baku dengan LI < 1,0 mengindikasikan tidak adanya risiko mengangkat untuk proses pengangkatan bahan baku.

\section{KESIMPULAN}

Proses penuangan bahan baku berupa cairan kimia yang saat ini dilakukan di PT. Yushiro Indonesia berpotensi menyebabkan terjadinya keluhan muskuloskeletal pada operator mixing. Keluhan ini terjadi karena penanganan material yang kurang baik pada saat proses penuangan cairan kimia, yang menyebabkan lifting index-nya $>1,0$.
Modifikasi dilakukan dengan mengubah alat bantu penimbangan menjadi table lifter serta perubahan jarak beban terhadap tubuh, sehingga lifting index-nya $<1,0$. Dengan demikian, perubahan penanganan ini bisa mengurangi keluhan muskuloskeletal pada operator.

\section{DAFTAR PUSTAKA}

Garndjean, E. 1993. Fitting the Task to the Man, 4th ed. Taylor and Francis Inc. London.

Wignjo Soebroto, Sritomo; 1996. Tata Letak Pabrik dan Pemindahan Bahan, Institut Teknologi Sepuluh November, Surabaya.

Wignjo Soebroto, Sritomo; 1995. Studi Gerak dan Waktu, Edisi pertama, PT. Guna Widya, Jakarta.

Madyana; 1996. Analisis Perancangan Kerja dan Ergonomi, Jilid I, Fakultas Teknologi Industri Universitas Atmajaya Yogyakarta.

Tarwaka; Hadi; Solichul dan Sudiajeng, Lilik; 1985. Ergonomi Untuk Kesehatan dan Keselamatan Kerja dan Produktivitas, UNIBA Press, Surakarta. 
